\title{
High Magnesium Calcite and Disordered Dolomite Growth on Leaf-cutting Ants: Challenges and Implications
}

\author{
Yihang Fang, Hongjie Li and Huifang Xu \\ University of Wisconsin-Madison, Madison, Wisconsin, United States
}

Calcium carbonate minerals are found in many biological systems starting from Proterozoic [1]. Magnesium calcite is rarely found in animal and only have been observed in some corals [2], coccolithophores [1] and sea urchin tooth [3]. The discovery of Mg-calcite and disordered dolomite on the leaf-cutting ants [4] is the first example in the insect. The leaf-cutting ants are a group of ants in the New World tropics and using fresh-cut leaves to cultivate fungus, which functions as their food source [5]. The decomposition of organic material, respiration, and fermentation in the fungus garden generate a large amount of carbon dioxide. Carbon dioxide concentration in the nest can reach up to 6\% [6], which is significantly higher than the current atmospheric level at $400 \mathrm{ppm}$. Therefore, the appearance of $\mathrm{Ca}-\mathrm{Mg}$ carbonate might have been a response to the combination of biotic and abiotic pressures.

In situ X-ray diffraction experiments were performed using a Rigaku Rapid II X-ray diffraction system with Mo K $\alpha$ radiation and a $100-\mu \mathrm{m}$ diameter collimator. A preliminary survey shows carbonate crystals are more concentrated on the torso, neck and sometimes head. Therefore, the legs were removed prior to the XRD runs and the torso was glued onto capillary tubes for XRD analyses. XRD confirmed that $\mathrm{Mg}$ calcite $(10 \%<\operatorname{mol} \% \mathrm{MgCO} 3<36 \%)$ or disordered dolomite $\left(\mathrm{mol} \% \mathrm{MgCO}_{3}>36 \%\right.$ and no cation ordering) are the only crystalline phase present on these leaf-cutting ants. Atta, the most evolved species, is the only one that does not possess any carbonate crystal. No " $b$ "-reflection or the ordering peaks has been observed in all samples. This could partially due to the high background from the chitin in the exoskeleton. Difference in $d_{104}$ values, which are affected by mol\% $\mathrm{MgCO}_{3}$ and cation ordering [7], varies across different ant species.

The XRD examined samples were then removed from the capillary tube and rinse with acetone to remove any remaining gel. The torso was then put into agar mortar for grinding in acetone. After removing the remnant ant's body parts, two or three drops of the acetone were then put onto copper grids for TEM. TEM experiments were done using a Philips CM200UT TEM instrument operating at $200 \mathrm{kV}$ acceleration voltage with $0.5 \mathrm{~mm}$ spherical aberration $(\mathrm{Cs})$ and a point resolution of $0.19 \mathrm{~nm}$. TEM examinations of leaf-cutting ants show that these Ca-Mg carbonates are smaller than $100 \mathrm{~nm}$ and highly heterogeneous. Selected-area electron diffraction (SAED) confirms that none of these $\mathrm{Ca}-\mathrm{Mg}$ carbonates have cation ordering.

The ants were vacuum epoxy impregnated, cut by a diamond blade, polished, and then coated with $1 \mathrm{~nm}$ iridium. Backscattered electron (BSE) images show that the Mg-calcite and disordered dolomite are precipitated on the exoskeleton. Also, electron microprobe analysis (EPMA) provides a quantitative $\sim 33$ mol\% $\mathrm{MgCO}_{3}$ for Acromyrmex. Based on the $d_{104}$ value from XRD and the chemical composition from EBSD, these Ca-Mg carbonates do not display any cation ordering according to a previous study [7]. Electron backscatter diffraction (EBSD) results show that the carbonates are heterogeneous in $\mathrm{MgCO}_{3}$ with one crystal but withhold a similar crystallographic orientation.

The evolutionary importance of precipitation of $\mathrm{Mg}$-calcite and disordered dolomite might have multiple aspects. Firstly, the crystalline carbonates provide a protective armor for the ants. Micro-indentation 
shows the Mg-calcite and disordered increased the exoskeleton hardness. Also, the precipitation of carbonate might have alleviated the high carbon dioxide concentration from the nest. Atta nest has ventilation design and resulted in a much lower $\mathrm{CO}_{2}$ level than nests of other leaf-cutting ants. The difference of $\mathrm{mol} \% \mathrm{MgCO}_{3}$ between species might have been a result of different $\mathrm{CO}_{2}$ concentrations in the nests.

The mechanism for promoting these carbonates are not explicit. In vitro experiments using Acromyrmex with Ir coated ants, sodium hydroxide washed ants, and normal ants demonstrated that only ants with intact exoskeleton surface structure can promote $\mathrm{Mg}$-calcite precipitation [4]. All other conditions only precipitated aragonite in the seawater-like solution. This indicates that the surface is promoting the nucleation and growth of the carbonate in the Mg-bearing solution. Previous analyses show that the carbonate-growing ant epicuticles contain phenylalanine (Phe) enriched protein [4]. However, synthesis with Phe-enriched protein in solution demonstrates no obvious effect to promote Mg-dehydration and no subsequent calcite/dolomite growth. Therefore, the exoskeleton surface may combine with the protein to provide a heterogeneous nucleation site. The understanding of the $\mathrm{Mg}$-calcite and disordered dolomite precipitation mechanism on the fungus-growing ants could also provide insights on the long persistent dolomite problem. The unique occurrence of dolomite on fungus-growing ants provides a well-constrained case for isolating individual factors contributing to the precipitation of dolomite precursor.
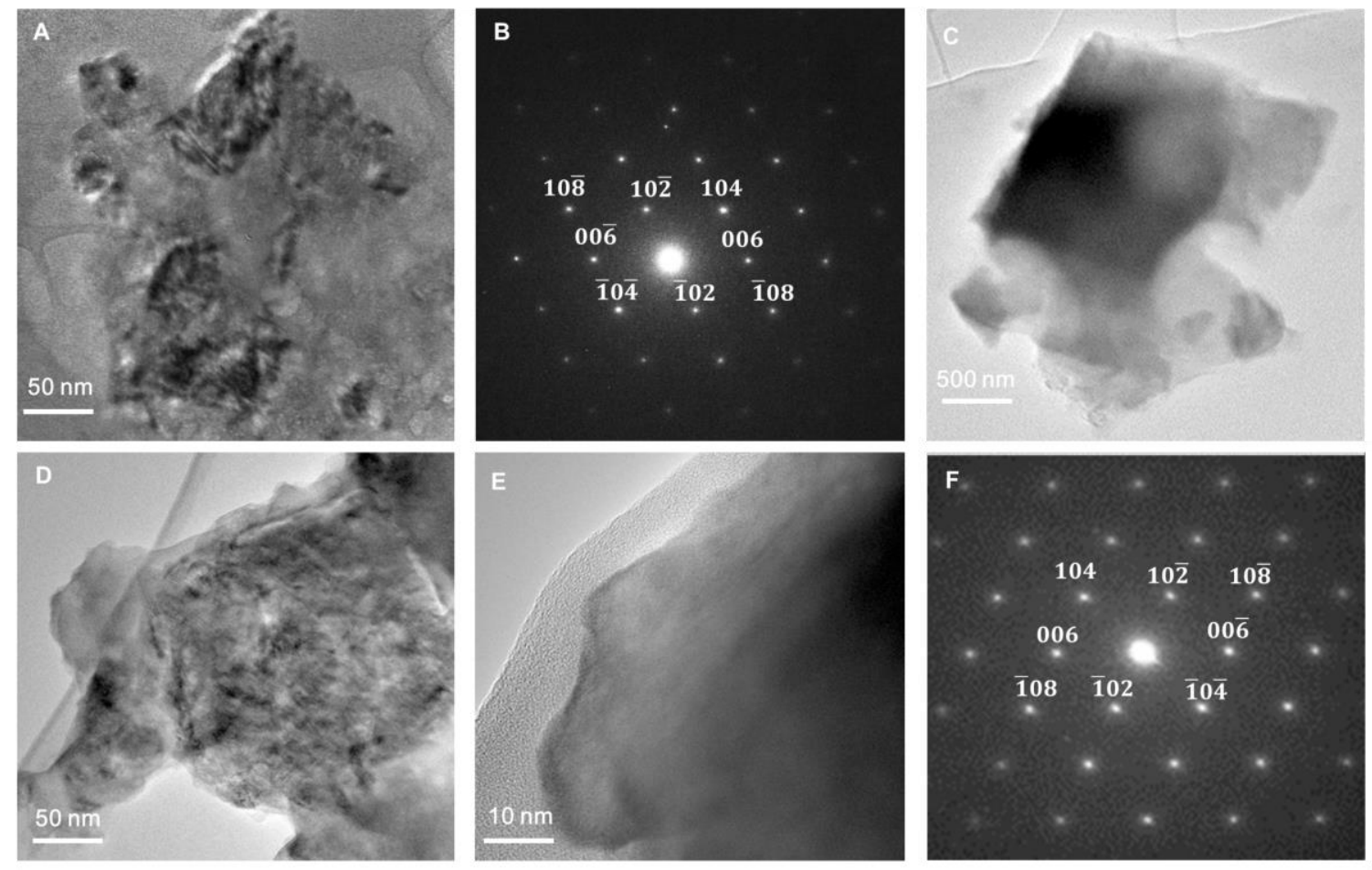

Figure 1. Figure 1. TEM images and SAED of disordered dolomite on Acromyrmex (A-B), Sericomyrmex (C-D), Trachymyrmex (E-F). 


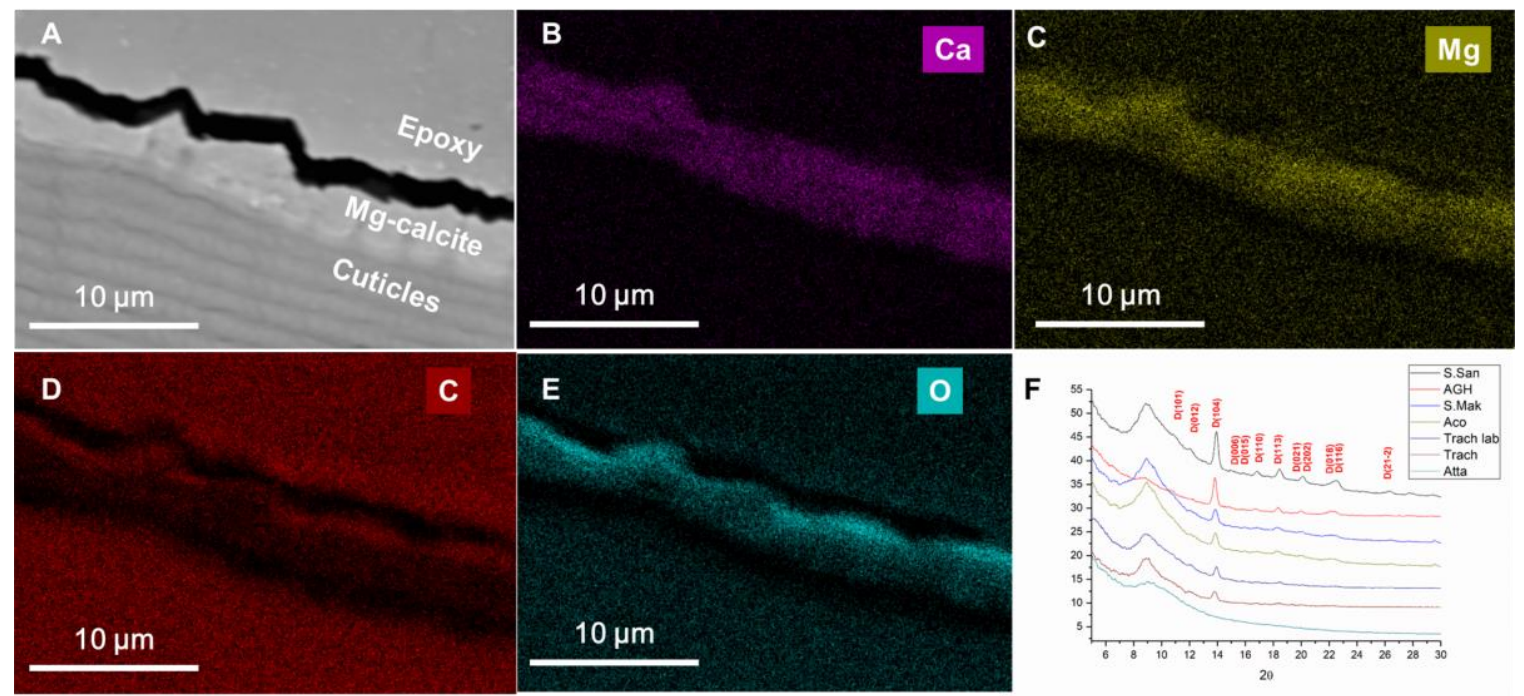

Figure 2. Figure 2.BSE image (A) and EDS elemental maps (B-E) of Acromyrmex. (F) XRD of different species of leaf-cutting ants.

\section{References}

1. Knoll, A. H. Biomineralization and Evolutionary History. Rev. Mineral. Geochemistry 2003, 54, 329356.

2. Nash, M. C.; Uthicke, S.; Negri, A. P.; Cantin, N. E. Ocean acidification does not affect magnesium composition or dolomite formation in living crustose coralline algae, Porolithon onkodes in an experimental system. Biogeosciences 2015, 12, 5247-5260, doi:10.5194/bg-12-5247-2015.

3. Killian, C. E.; Metzler, R. A.; Gong, Y.; Churchill, T. H.; Olson, I. C.; Trubetskoy, V.; Christensen, M. B.; Fournelle, J. H.; De Carlo, F.; Cohen, S.; Mahamid, J.; Scholl, A.; Young, A.; Doran, A.; Wilt, F. H.; Coppersmith, S. N.; Gilbert, P. U. P. A. Self-sharpening mechanism of the sea urchin tooth. Adv. Funct. Mater. 2011, 21, 682-690, doi:10.1002/adfm.201001546.

4. Li, H.; Sun, C.-Y.; Fang, Y.; Carlson, C. M.; Xu, H.; Jesovnik, A.; Sosa-Calvo, J.; Zarnowski, R.; Bechtel, H. A.; Fournelle, J. H.; Andes, D. R.; Schultz, T. R.; Gilbert, P. U. P. A.; Currie, C. R. Dolomite armor in ants. Proc. Natl. Acad. Sci. 2020, in review.

5. Li, H.; Sosa-Calvo, J.; Horn, H. A.; Pupo, M. T.; Clardy, J.; Rabeling, C.; Schultz, T. R.; Currie, C. R. Convergent evolution of complex structures for ant-bacterial defensive symbiosis in fungus-farming ants. Proc. Natl. Acad. Sci. U. S. A. 2018, 115, 10720-10725, doi:10.1073/pnas.1809332115.

6. Römer, D.; Bollazzi, M.; Roces, F. Carbon dioxide sensing in an obligate insectfungus symbiosis: CO2 preferences of leafcutting ants to rear their mutualistic fungus. PLoS One 2017, 12, 1-17, doi:10.1371/journal.pone.0174597.

7. Fang, Y.; Xu, H. A new approach to quantify the ordering state of protodolomite using xrd, tem, and zcontrast imaging. J. Sediment. Res. 2019, 89, doi:10.2110/jsr.2019.29. 